Open Access

\title{
Withholding or withdrawal of treatment under French rules: a study performed in 43 intensive care units
}

Olivier Lesieur ${ }^{1,2^{*}}$, Maxime Leloup ${ }^{1}$, Frédéric Gonzalez ${ }^{2,3}$, Marie-France Mamzer ${ }^{2}$ and EPILAT study group

\begin{abstract}
Background: In France, decisions to limit treatment fall under the Leonetti law adopted in 2005. Leading figures from the French world of politics, science, and justice recently claimed for amendments to the law, considering it incomplete. This study, conducted before any legislative change, aimed to investigate the procedural aspects of withholding/withdrawing treatment in French ICUs and their adequacy with the existing law.

Methods: The characteristics of patients qualified for a withholding/withdrawal procedure were prospectively collected in 43 French ICUs. The study period (60 or 90 days under normal operating conditions) took place in the first half of 2013.

Results: During the study period, 777 (14\%) of 5589 admitted patients and 584 (52\%) of 1132 patients dying in the ICU had their treatment withheld or withdrawn. Whereas 344 patients had treatment(s) withheld (i.e., not started or not increased if already engaged), 433 had one or more treatment(s) withdrawn. Withdrawal of treatment was applied in 156 of 223 (70 \%) brain-injured patients, compared to 277 of 554 (50\%) patients with other reasons for admission $(p<0.01)$. At the time of the decision-making, the patient's wishes were known in $181(23 \%)$ of the 777 cases in one or more different way(s): 73 (9.4\%) from the patient, 10 (1.3\%) by advance directives, 10 (1.3\%) through a designated trusted person, and $108(13.9 \%)$ reported by the family or close relatives. An external consultant was involved in less than half of all decisions (356 of 777, $46 \%$ ). Of the 777 patients qualified for a withholding/ withdrawal procedure, 133 (17\%) were discharged alive from the hospital (126 after withholding, 7 after withdrawal).

Conclusions: More than half of deaths in the study population occurred after a decision to withhold or withdraw treatment. Among patients under withholding/withdrawal procedures, brain-injured subjects were more likely to undergo a withdrawal procedure. The prevalence of advance directives and designated trusted persons was low. Because patients' preferences were unknown in more than three quarters of cases, decisions remained primarily based on medical judgment. Limitations, especially withholding of treatment, did not preclude survival and hospital discharge.
\end{abstract}

Keywords: Withholding treatment; Life support care; Medical futility; Prognosis; Brain injury; Advance directives

\footnotetext{
* Correspondence: olivier.lesieur@gmail.com

1 Réanimation, CH Saint-Louis, 17019 La Rochelle, France

${ }^{2}$ EA 4569, Université Paris Descartes, 75006 Paris, France

Full list of author information is available at the end of the article
} 


\section{Background}

Several decades ago, most patients who suddenly died in the hospital underwent cardiopulmonary resuscitation before death. From the 1950s onward, the development of artificial life-sustaining and/or organ-substituting techniques delivered in intensive care units (ICUs) has shifted the definition of death from a sudden and unexpected event to a partially controlled process. Far from searching to avoid death "at any cost" irrespective of the ensuing living conditions, the primary goal of intensive care is to return the highest number of critically ill patients to a quality of life they would find acceptable [1]. Because interfering in the dying process is not always in the patient's best interest, life-prolonging therapies may be withheld or withdrawn when they are deemed "futile."

Substantial variability exists between countries, institutions, and physicians in the decision to withhold or withdraw (WhWd) life-sustaining treatment in critically ill patients [2-10]. At an individual level, available prognostic indexes are not accurate enough to make definite end-of-life decisions without foretelling a destiny that would become self-fulfilling ("self-fulfilling prophecy") $[5,11,12]$. Moreover, withholding/withdrawal decisionmaking may be considered by stakeholders (patients, relatives, and caregivers) with different hopes and preferences influenced by age, gender, religion, culture, education, training, and geography [5, 10, 13-20]. Legislation, case mix, availability of ICU resources, and organization of care in the institution/region may also influence physicians' attitude towards end-of-life care [4, 21]. Furthermore, the lack of a consensus-based model for decision-making may favor variability in withholding/ withdrawal decisions, published guidelines mainly focusing on general principles rather than practical details $[22,23]$.

In France, the decision to withhold or withdraw treatment falls under the law $n^{\circ} 2005-370$ of April 22, 2005 related to patients' rights and to the end-of-life (so-called Leonetti law), which authorizes the withholding or withdrawal of curative therapies when deemed "useless, disproportionate or to have no other effect than solely the artificial preservation of life" [24]. Continuing such treatment with no hope of benefit or cure would equate to an undue therapeutic obstinacy, especially for patients who are no longer able to express their wishes. In this setting, when current or further life-sustaining treatments appear to be of no overall benefit for a patient, the law stipulates that any WhWd decision should only be made after a formal procedure of collegial deliberation [23, 24]. Obtaining an external opinion from an independent consultant is a compulsory part of the procedure. In addition to medical factors, the Leonetti law specifies that the discussion must integrate the patient's wishes spontaneously expressed or written in advance directives, the opinion of the trusted person (if appointed), and the family and/or close relatives.

Leading figures from the French world of politics, science, and law recently claimed for amendments to the law reinforcing patients' rights. The aims of this prospective observational study, conducted before any legislative changes, were to investigate the incidence of withholding/withdrawal decisions in French ICUs and to evaluate how these procedures were implemented with regard to the legislation in force.

\section{Methods}

This report is a secondary analysis of a previous study designed to assess the theoretical eligibility as organ donors of patients deceased after end-of-life decisions [25]. The study was performed in 43 French ICUs (15 units in university-affiliated centers, 28 in general hospitals). The institutional review board (CPP Paris Ile de France II, IRB registration: 00001072) approved the protocol. The study period (60 or 90 consecutive days in normal operating conditions) took place during the first half of 2013. All patients admitted to the ICU who underwent a WhWd procedure according to the terms of the French Leonetti law were enrolled in the survey.

The epidemiological data recorded during the ICU stay included age, gender, medical history, reasons for admission, Simplified Acute Physiology Score (SAPS) II index [26], Knaus [27], McCabe [28], and Charlson [29] scores on admission, relevant clinical and biological characteristics, Sequential Organ Failure Assessment (SOFA) score [30] at the time of the WhWd decision, reasons for the decision, implemented measures, and outcome of the patient (deceased or discharged alive). By convention, a SOFA organ sub-score of 3 or more was considered as an organ failure. WhWd patients discharged from the ICU were followed until discharge from the hospital or death in the ward.

For WhWd patients, we analyzed how the limitations were carried out with regard to the contribution of caregivers in end-of-life decisions (including consultant physicians), patient or surrogate decision-maker involvement, and advance directives. Reasons for limiting treatment (based on items proposed by the French intensive care society [23]), participants in the decision-making process, and type of treatment withheld or withdrawn were registered by the local investigator using a form developed for this purpose.

Limitations differentially included withholding or/and withdrawing therapies like cardiopulmonary resuscitation, endotracheal intubation, ventilatory support, renal replacement therapy, inotrope use, urgent surgery, antimicrobial therapy, blood product transfusion, nutrition, and hydration. A three-level hierarchy for classifying decisions used the more active mode of limitation ("stop" > "do not 
increase" > "do not start") if more than one was performed. "Withdrawing" was defined as the decision to stop a treatment already undertaken. "Withholding" was defined as the decision not to start or increase a treatment beyond a critical threshold. Patients were classified as "withheld (Wh) patient" if withholding was the single limitation made and as "withdrawn (Wd) patient" if treatments were both withheld and withdrawn. Within the Wh sub-group, the patients who had one or more "do not increase" order(s) were compared to those exclusively qualified for "do not start" instruction(s).

\section{Statistical analysis}

Results are expressed as mean \pm standard deviation (SD) or median and interquartile (IQR) for continuous variables and percentage with $95 \%$ confidence interval (CI) for categorical variables. Simple regression analysis was used to establish the relationship between continuous variables (SAPS II, mortality rate) and the WhWd decision rates among the 43 participating ICUs. Comparisons of patients were based on $t$ test or the Mann-Whitney $U$ test for continuous variables and on chi-square $\left(x^{2}\right)$ test or Fisher's exact test for categorical variables, as appropriate. A two-tailed $p$ value $<0.05$ was considered statistically significant. We used univariate and multivariate logistic regression analyses with $\mathrm{Wh} / \mathrm{Wd}$ as a binary procedural variable to assess associations with categorical variables. All relevant univariate indexes with $p$ value less than 0.2 were included in the multivariate logistic regression model (age > 70 years, comorbidities, reasons for admission, organ failures). Descriptive statistics, univariate, and multivariate regressions were performed using Epi Info ${ }^{\mathrm{TM}}$ (Centers for Disease Control and Prevention, Atlanta, GA) and the $\mathrm{R}$ statistical package ( $\mathrm{R}$ Core Team, $\mathrm{R}$ Foundation for Statistical Computing, Vienna, Austria).

\section{Results \\ Study population}

During the study period, 5589 patients (age: $62 \pm 17$ years; gender ratio M/F: 1.6; SAPS II: $44 \pm 22$ ) were admitted to 43 ICUs (616 beds). A total of 4457 patients (80\%) were discharged alive from the ICU. One thousand one hundred thirty-two patients $(20 \%)$ died in the ICU. The median (IQR) mortality rate across the 43 participating ICUs was $20.8(17-25) \%$. Over half of the deceased patients (584/1132, $52 \%)$ underwent a formalized WhWd procedure before death.

Of the 5589 patients admitted, 777 (14\%; age: $68 \pm 14$ years; gender ratio M/F: 1.8; SAPS II: $60 \pm 20$; SOFA: 7 [4-11]) underwent Wh (344 patients, $6 \%$ ) and/or Wd (433 patients, $8 \%$ ) measures (Figs. 1 and 2). Table 1 shows the study population for each participating ICU with regard to end-of-life decisions and outcome (deceased or discharged alive). The median (IQR), minimum, and maximum proportions of WhWd patients across the 43 ICUs were 13.2 (10-19), 4, and $30 \%$, respectively. The proportion of WhWd patients across the 43 ICUs correlated with SAPS II $(p<0.02$, Fig. 3a) and mortality rates $(p<0.001$, Fig. $3 \mathrm{~b})$. Baseline data, reasons for admission, and outcome of the $777 \mathrm{WhWd}$ patients are shown in Tables 2 (all) and 3 (separating Wh and Wd).

\section{WhWd decision-making}

Whatever the procedure (Wh or Wd), the median (IQR) time from the ICU admission to the WhWd decision was 4 (1-13) days. At the time of the decision-making, the patient's wishes were known in 181 cases $(23 \%)$, on the basis of one or more different source(s) of information: spontaneously voiced (73 cases, $9.4 \%$ ), written in advance directives (10 cases, $1.3 \%)$, expressed by a designated trusted person (10 cases, $1.3 \%$ ), and/or reported by the family or close relatives (108 cases, $13.9 \%$ ). An external consultant physician was involved in the decision-making process in less than half of the 777 cases (356 patients, $46 \%): 142 / 344$ (41.3 \%) and 214/433 (49.4\%) cases for Wh and $\mathrm{Wd}$, respectively $(p<0.05)$.

The rationales most often claimed to justify the WhWd decision were the following:

1) No additional information needed for decision-making: 602 patients $(77 \%)$

2) Limited subsequent functional autonomy: 581 patients $(75 \%)$

3) Absence of curative strategy: 559 patients (72\%)

4) Non-responsive to medical therapy: 516 patients (66 \%)

5) Advanced or terminal stage of a severe and incurable disease: 474 patients $(61 \%)$

6) Limited subsequent relational quality of life: 442 patients (57\%)

7) Limited functional autonomy before hospital admission: 317 patients (41\%)

8) Very advanced age: 210 patients (27\%)

9) Perception of disproportionate and non-beneficial treatment voiced by patient's relatives: 172 patients (22\%)

10)Wish to limit treatment voiced by patient: 110 patients $(14 \%)$

Table 4 shows organ failures, treatment engaged, and rationales for WhWd at the time of the decisionmaking, separating Wh and Wd.

\section{Implemented measures}

The WhWd measures implemented are detailed in Fig. 4 separating "do not start," "do not increase" (Fig. 4a), and "stop" orders (Fig. 4b). After a first WhWd order, 89 patients $(11.5 \%)$ received additional measures for limitation of therapy. Endotracheal ventilation was the life-sustaining 


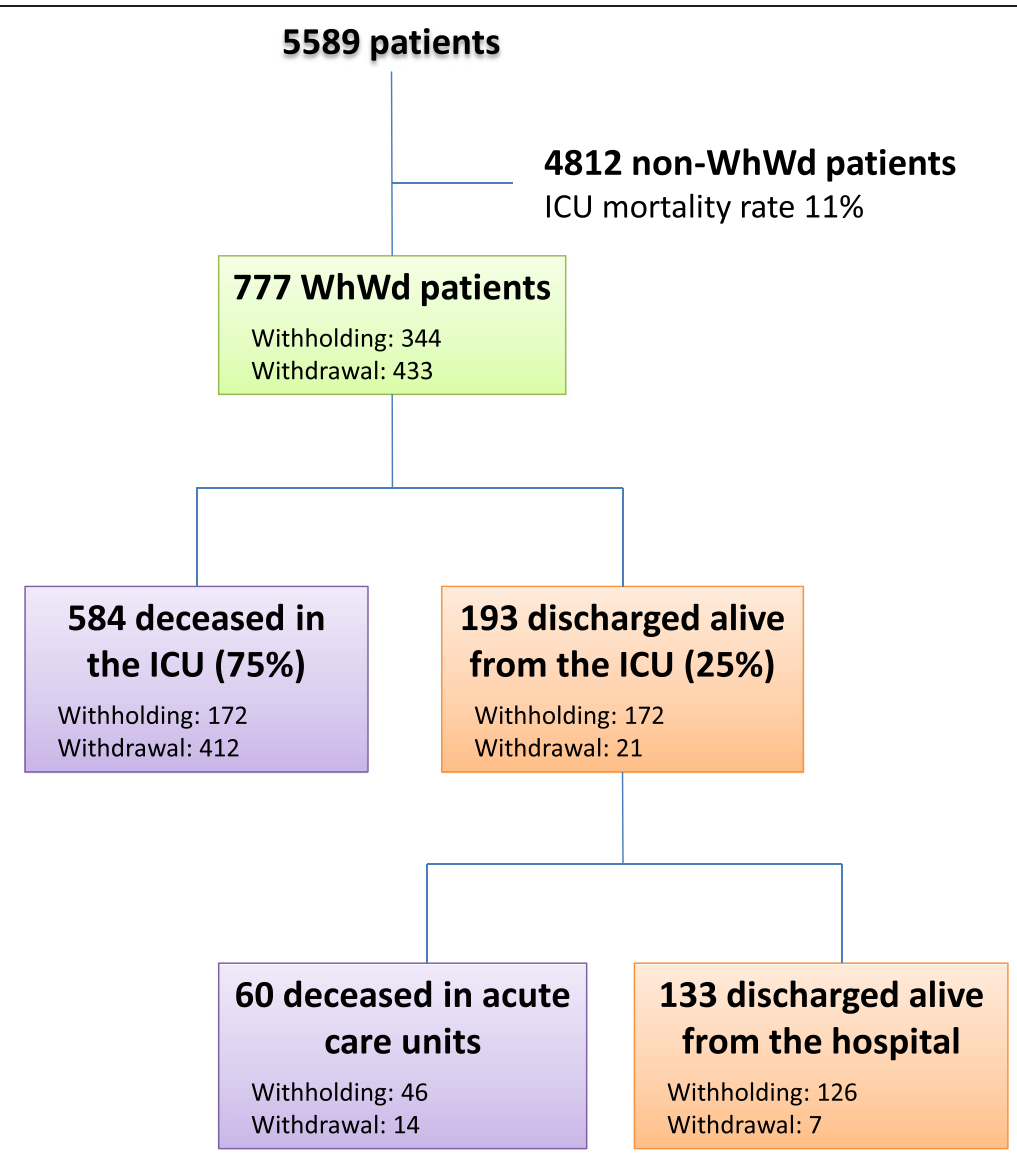

Fig. 1 Flow chart. WhWd withhold or withdraw treatment, ICU intensive care unit

treatment most often engaged at the time of the decisionmaking (375 patients) and subsequently withdrawn (227), with (147) or without (80) removal of the endotracheal tube.

Withdrawal of treatment was applied in 156 of 223 (70\%) brain-injured patients, compared to 277 of 554 (50\%) patients with other reasons for admission pooled, who had treatment equally withheld or withdrawn $(p<0.01)$. WhWd patients with chronic respiratory diseases and/ or respiratory failure as reason for admission had treatment preferentially withheld than withdrawn (Table 3). For the WhWd patients classified C or D on the Knaus scale, those with cognitive impairment (Table 3), and/or those for whom "limited autonomy before admission" was

\begin{tabular}{lcccccccc}
\hline & \multicolumn{1}{c}{ All } & \multicolumn{3}{c}{ Non-WhWd patients } & \multicolumn{3}{c}{ WhWd patients } \\
& $\begin{array}{c}\text { patients } \\
N=5589\end{array}$ & All* & Alive & CDD & BDD & All* & Alive & Deceased \\
& & & $\begin{array}{c}N=4264 \\
(88.6 \%)\end{array}$ & $\begin{array}{c}N=450 \\
(9.4 \%)\end{array}$ & $\begin{array}{c}N=98 \\
(2 \%)\end{array}$ & $N=777$ & $\begin{array}{c}N=193 \\
N=584 \\
(24.8 \%)\end{array}$ & $(75.2 \%)$ \\
\hline Age (years) & $64(52-75)$ & $63(50-74)$ & $62(49-73)$ & $70(59-78)$ & $59(48-70)$ & $70(61-79)$ & $70(62-82)$ & $70(60-79)$ \\
M/F & 1.6 & 1.6 & 1.6 & 1.8 & 1.1 & 1.8 & 1.7 & 1.9 \\
SAPS II & $40(28-56)$ & $38(26-52)$ & $35(25-48)$ & $70(53-90)$ & $6052-71)$ & $59(47-71)$ & $50(40-61)$ & $62(49-76)$ \\
LOS (days) & $4(2-9)$ & $4(2-8)$ & $4(2-8)$ & $6(0-9)$ & $2(0-9)$ & $8(3-20)$ & $9(4-25)$ & $7(3-18)$ \\
\hline
\end{tabular}

Age, SAPS II and LOS are given as median (IQR).

(*) Age, SAPS II and LOS were significantly higher in WhWd versus non-WhWd patients $(\mathrm{p}<0.01)$

Fig. 2 Characteristics of patients admitted over the study period. WhWd withhold or withdraw treatment, Alive discharged alive from the ICU, CDD circulatory determination of death, BDD brain determination of death, deceased in the ICU, M/F sex ratio, SAPS Simplified ACute Physiology Score, LOS length of stay 
Table 1 Study population in the 43 participating ICUs

\begin{tabular}{|c|c|c|c|c|c|c|c|c|c|}
\hline ICU & Hospital & $\begin{array}{l}\mathrm{ICU} \\
\text { beds, } \\
N\end{array}$ & $\begin{array}{l}\text { ICU } \\
\text { admissions, } \\
N\end{array}$ & $\begin{array}{l}\text { Mean } \\
\text { age, years }\end{array}$ & $\begin{array}{l}\text { Mean } \\
\text { SAPS ॥ }\end{array}$ & $\begin{array}{l}\text { In-ICU death } \\
\text { rate, } \%\end{array}$ & $\begin{array}{l}\text { WhWd patients, } N \\
\text { (\% admissions) }\end{array}$ & $\begin{array}{l}\text { Wh/Wd } \\
\text { patients N/N }\end{array}$ & $\begin{array}{l}\text { Discharged alive from the ICU after } \\
\text { WhWd, N (\% WhWd) }\end{array}$ \\
\hline 1 & General & 12 & 48 & 58 & 35 & 10 & $4(8)$ & $1 / 3$ & $1(25)$ \\
\hline 2 & General & 10 & 48 & 68 & 49 & 21 & $4(8)$ & $2 / 2$ & $2(50)$ \\
\hline 3 & General & 8 & 49 & 64 & 45 & 24 & $2(4)$ & $0 / 2$ & $1(50)$ \\
\hline 4 & General & 12 & 63 & 67 & 48 & 22 & $12(19)$ & $1 / 11$ & $0(0)$ \\
\hline 5 & University & 9 & 71 & 52 & 39 & 17 & $7(10)$ & $0 / 7$ & $0(0)$ \\
\hline 6 & General & 8 & 78 & 62 & 39 & 19 & $17(22)$ & $14 / 3$ & $6(35)$ \\
\hline 7 & General & 12 & 83 & 70 & 47 & 31 & $25(30)$ & $11 / 14$ & $5(20)$ \\
\hline 8 & General & 10 & 86 & 64 & 44 & 19 & $15(17)$ & $11 / 4$ & $4(27)$ \\
\hline 9 & General & 8 & 87 & 66 & 44 & 20 & $16(18)$ & $14 / 2$ & $4(25)$ \\
\hline 10 & General & 8 & 89 & 63 & 44 & 21 & $18(20)$ & $9 / 9$ & $5(28)$ \\
\hline 11 & University & 15 & 96 & 61 & 44 & 23 & $12(13)$ & $5 / 7$ & $2(17)$ \\
\hline 12 & General & 10 & 96 & 64 & 47 & 20 & $12(13)$ & $5 / 7$ & $4(33)$ \\
\hline 13 & General & 12 & 99 & 61 & 48 & 21 & $7(7)$ & $1 / 6$ & $1(14)$ \\
\hline 14 & General & 12 & 102 & 64 & 52 & 26 & $26(25)$ & $17 / 9$ & $12(46)$ \\
\hline 15 & University & 15 & 106 & 65 & 48 & 19 & $21(20)$ & $2 / 19$ & $1(5)$ \\
\hline 16 & General & 12 & 109 & 68 & 46 & 20 & $10(9)$ & $2 / 8$ & $1(10)$ \\
\hline 17 & General & 17 & 111 & 61 & 50 & 30 & $26(23)$ & $15 / 11$ & $10(38)$ \\
\hline 18 & University & 15 & 112 & 57 & 55 & 35 & $18(16)$ & $7 / 11$ & $4(22)$ \\
\hline 19 & University & 15 & 118 & 59 & 46 & 25 & $20(17)$ & $5 / 15$ & $3(15)$ \\
\hline 20 & General & 12 & 119 & 58 & 38 & 15 & $23(19)$ & $11 / 12$ & $8(35)$ \\
\hline 21 & General & 10 & 121 & 60 & 40 & 17 & $21(17)$ & $14 / 7$ & $3(14)$ \\
\hline 22 & University & 14 & 123 & 66 & 54 & 33 & $23(19)$ & $8 / 15$ & $4(17)$ \\
\hline 23 & University & 12 & 125 & 50 & 26 & 21 & $17(14)$ & $2 / 15$ & $0(0)$ \\
\hline 24 & General & 14 & 126 & 61 & 51 & 29 & $18(14)$ & $1 / 17$ & $0(0)$ \\
\hline 25 & General & 12 & 129 & 63 & 39 & 21 & $16(12)$ & $3 / 13$ & $2(13)$ \\
\hline 26 & University & 26 & 132 & 56 & 39 & 18 & $16(12)$ & $7 / 9$ & $8(50)$ \\
\hline 27 & General & 15 & 132 & 61 & 49 & 22 & $10(8)$ & $4 / 6$ & $1(10)$ \\
\hline 28 & General & 10 & 135 & 69 & 48 & 15 & $6(4)$ & $3 / 3$ & $2(33)$ \\
\hline 29 & General & 18 & 135 & 63 & 51 & 23 & $27(20)$ & $9 / 18$ & $9(33)$ \\
\hline 30 & General & 16 & 141 & 66 & 55 & 31 & 27 (19) & $23 / 4$ & $7(26)$ \\
\hline 31 & General & 12 & 152 & 65 & 51 & 31 & $38(25)$ & $23 / 15$ & $14(37)$ \\
\hline 32 & General & 23 & 154 & 58 & 46 & 21 & $16(10)$ & $7 / 9$ & $7(44)$ \\
\hline 33 & University & 12 & 156 & 59 & 40 & 12 & $20(13)$ & $9 / 11$ & $6(30)$ \\
\hline 34 & General & 22 & 156 & 64 & 51 & 20 & $36(23)$ & $20 / 16$ & $16(44)$ \\
\hline 35 & University & 15 & 159 & 58 & 38 & 14 & $12(8)$ & $9 / 3$ & $2(17)$ \\
\hline 36 & University & 22 & 171 & 59 & 45 & 25 & $19(11)$ & $6 / 13$ & $0(0)$ \\
\hline 37 & University & 11 & 181 & 69 & 28 & 8 & $9(5)$ & $3 / 6$ & $4(44)$ \\
\hline 38 & University & 20 & 182 & 57 & 44 & 16 & $24(13)$ & $7 / 17$ & $8(33)$ \\
\hline 39 & General & 18 & 183 & 65 & 46 & 23 & $19(10)$ & $8 / 11$ & $2(11)$ \\
\hline 40 & General & 25 & 224 & 62 & 42 & 20 & 34 (15) & $5 / 29$ & $2(6)$ \\
\hline
\end{tabular}


Table 1 Study population in the 43 participating ICUs (Continued)

\begin{tabular}{|c|c|c|c|c|c|c|c|c|c|}
\hline 41 & General & 18 & 240 & 60 & 41 & 18 & $28(12)$ & $13 / 15$ & $7(25)$ \\
\hline 42 & University & 15 & 266 & 59 & 35 & 11 & $15(6)$ & $13 / 2$ & $6(40)$ \\
\hline \multirow[t]{2}{*}{43} & University & 24 & 296 & 61 & 45 & 13 & $31(10)$ & $14 / 17$ & $9(29)$ \\
\hline & All & 616 & 5589 & & & & 777 (14) & $344 / 433$ & $193(25)$ \\
\hline
\end{tabular}

SAPS Simplified Acute Physiology Score, WhWd withhold or withdraw treatment, ICU intensive care unit

a rationale to justify WhWd (Table 4), treatment was more likely to be withheld than withdrawn. In a multivariate analysis, neurological (OR 4.5; 95 \% CI 3.3-6.2), hematological (2.4; $1.3-4.6)$, renal $(1.8 ; 1.2-2.6)$, and circulatory $(1.5 ; 1.1-$ 2.1) failures at the time of the decision were significantly associated with Wd vs Wh.

Among the 344 Wh patients, 105 only had "do not start" instructions prohibiting cardiopulmonary resuscitation (91), renal replacement therapy (72), inotrope use (64), endotracheal (58) or non-invasive (20) ventilation, surgery (51), blood product transfusion (35), antibiotics (17), and oxygenation (1). Compared to the 239 Wh patients who had "do not start" and/or "do not increase" instructions, these 105 patients had lower median SAPS II (49 vs 57 ), total SOFA score (4 vs 6 ), rate of respiratory (22 vs $40 \%$ ) and circulatory (17 vs $35 \%$ ) failures, and death rate (33 vs $57 \%$ ) in the ICU $(p<0.01)$. Conversely, chronic respiratory diseases were more frequent in this group (48 vs $33 \%$ ).

\section{Patients' outcome}

Of the 4812 patients without WhWd measures, 4264 (89\%) left the ICU alive, while 548 (11\%) died in the ICU.

Of the 777 WhWd patients, 193 (25\%) survived and were discharged from the ICU, whereas 584 (75\%) died in the ICU. The median (IQR) time from withholding/ withdrawal completion to death in the ICU was 2 days (1-6) after withholding (172/344 deaths after Wh, $50 \%)$, and 1 day (0-3) after withdrawal (412/433 deaths after
Wd, $95 \%)$. Sixty more WhWd patients died on the ward after discharge from the ICU, which means that 133 patients (17\% of all WhWd patients) were discharged alive from the hospital (Fig. 1).

\section{Discussion}

Contrary to ethicists [21, 22, 31], many intensivists clearly distinguish between withholding and withdrawal decisions, with the former being perceived as more "passive” [3, 4, 10, 32, 33]. Physicians' unwillingness to withdraw life-sustaining therapy has been previously associated with religion, culture, experience, and gender [14, 33-37]. Rather than focusing on differences between centers, our study aimed to identify the conditions that specifically led to withdraw and/or withhold therapy. By establishing a three-level hierarchy of decisions ("stop" > "do not increase" > "do not start"), we demonstrated that more "active" limitations involved patients with acute organ failures, high severity indexes, and great dependence on lifesustaining therapy. Brain-injured patients were also more likely to undergo a withdrawal procedure, whereas patients with chronic respiratory disease, pre-existing disability affecting autonomy or cognition, and/or respiratory failure on admission had treatment preferentially witheld than withdrawn. Whatever the level of limitation applied, the patient's wishes were unknown in more than three quarters of cases at the time of the decision-making. Thus, decisions to limit treatment were predominantly based on medical judgment. Amazingly, while withdrawals of life-sustaining
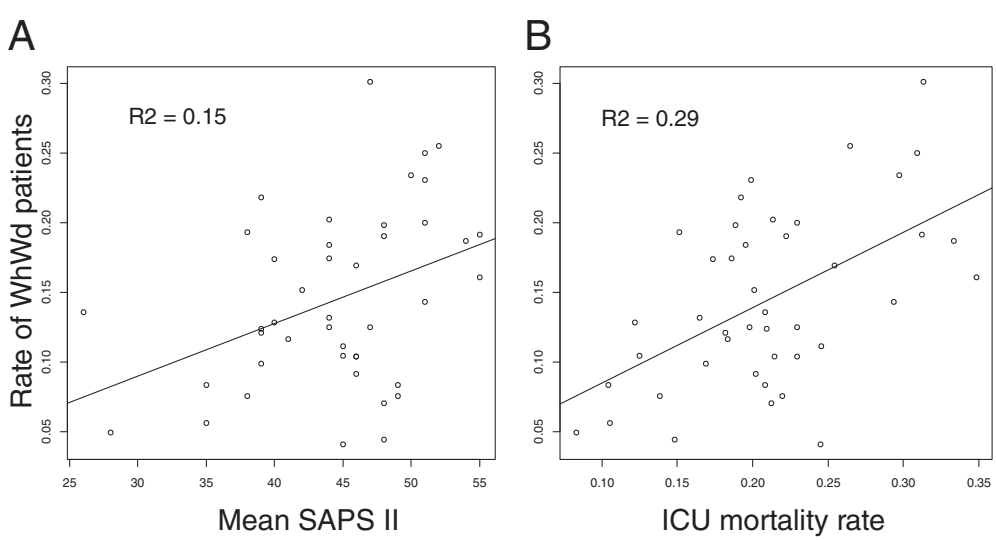

Fig. 3 Relationship between SAPS II (a), mortality rate (b), and WhWd decision rate among the 43 participating ICUs. SAPS Simplified Acute Physiology Score, WhWd withhold or withdraw treatment, ICU intensive care unit 
Table 2 Baseline data of the 777 WhWd patients

\begin{tabular}{lllll}
\hline & & Number & Percent & $95 \% \mathrm{Cl}$ \\
\hline Knaus & $\mathrm{A}$ & 185 & 24 & $21.0-27.2$ \\
& $\mathrm{~B}$ & 224 & 29 & $25.9-32.4$ \\
& $\mathrm{C}$ & 276 & 35.8 & $32.4-39.3$ \\
& $\mathrm{D}$ & 87 & 11.3 & $9.2-13.8$ \\
Mc Cabe & MD & 5 & & \\
& 0 & 315 & 40.9 & $37.4-44.4$ \\
& 1 & 299 & 38.8 & $35.3-42.3$ \\
& 2 & 157 & 20.4 & $17.6-23.4$ \\
& MD & 6 & &
\end{tabular}

Risk factors

\begin{tabular}{|c|c|c|c|}
\hline Hypertension & 385 & 49.6 & $46.0-53.2$ \\
\hline Tobacco & 238 & 30.7 & $27.5-34.1$ \\
\hline Diabetes & 183 & 23.6 & $20.7-26.8$ \\
\hline Dyslipidemia & 175 & 22.6 & $19.7-25.7$ \\
\hline Alcohol & 159 & 20.5 & $17.7-23.5$ \\
\hline \multicolumn{4}{|l|}{ Chronic diseases } \\
\hline Cardiac & 282 & 36.3 & $32.9-39.8$ \\
\hline Pulmonary & 235 & 30.2 & $27.1-33.6$ \\
\hline Neurological & 130 & 16.7 & $14.2-19.6$ \\
\hline Renal & 109 & 14.0 & $11.7-16.7$ \\
\hline Vascular & 101 & 13.0 & $10.8-15.6$ \\
\hline Hepatic & 77 & 9.9 & $7.9-12.3$ \\
\hline Intestinal & 54 & 6.9 & $5.3-9.0$ \\
\hline \multicolumn{4}{|l|}{ Neurological deficit } \\
\hline Cognition & 94 & 12.1 & $9.9-14.6$ \\
\hline Swallowing & 46 & 5.9 & $4.4-7.9$ \\
\hline Hemiplegia & 22 & 2.8 & $1.8-4.3$ \\
\hline Tetraplegia & 11 & 1.4 & $0.7-2.6$ \\
\hline Malignancies & 221 & 28.4 & $25.3-31.8$ \\
\hline Rare diseases & 44 & 5.7 & $4.2-7.6$ \\
\hline \multicolumn{4}{|l|}{ Reason for ICU admission } \\
\hline Respiratory failure & 259 & 33.3 & $30.0-36.8$ \\
\hline Shock and MOF & 215 & 27.7 & $24.6-31.0$ \\
\hline Post-cardiac arrest coma & 150 & 19.3 & $16.6-22.3$ \\
\hline Stroke & 49 & 6.3 & $4.7-8.3$ \\
\hline Head trauma & 24 & 3.1 & $2.0-4.6$ \\
\hline Other & 80 & 10.3 & $8.3-12.7$ \\
\hline
\end{tabular}

WhWd withhold or withdraw treatment, ICU intensive care unit, MOF multiple organ failure, $\mathrm{Cl}$ confidence interval, $M D$ missing data

treatment (with hastening of death as a possible risk) were thoroughly argued, a consultant physician was involved at the level of the decision-making in less than half cases.

There is an extensive literature based on questionnaire and epidemiological surveys exploring attitudes of intensive care physicians on forgoing treatments. Influenced by multiple factors, practices vary considerably between and within countries $[3,4,10,32,38-40]$. Although most Western physicians consider withholding/withdrawing treatment usual, respondents to a recent multinational survey in Asia reported that they commonly withheld (70.2 \%) but rarely withdrew $(20.7 \%)$ treatments [10]. In a hypothetical scenario of post-anoxic coma with septic shock, Asian physicians are less likely to withhold or withdraw life-sustaining treatments, and more likely to "do everything" (53.8 \%) than those in Western countries (USA $<40 \%$, Southern Europe $<30 \%$, Canada $<20 \%$, Australia $<10 \%$, Northern and Central Europe < $10 \%)$ [10, 32, 38]. In 37 ICUs from 17 European countries (2000-2001), Sprung found that $76 \%$ of deaths were preceded by some kind of limitation, with a clear downward North/South tendency between regions. Amazingly, the French centers who volunteered to take part in the survey could not obtain approval from their ethics committee [3]. However, despite inter-unit variability, our data are close to those collected in 1997 by the French LATAREA group in terms of proportion of ICU patients undergoing WhWd measures (14 vs $11 \%$ ) or dying after a decision to limit life-supporting therapies (52 vs $53 \%$ ) and proportion of withholding/withdrawal decisions (41/59 vs 44/56 \%) [2]. These two French surveys were completed 16 years apart, the former (LATAREA) before and the latter (EPILAT) after enactment of the Leonetti law. Considering such apparently limited impact on WhWd rates (despite the higher median age and SAPS II in our study population), one could argue that the law provided a legal framework for practices that already existed informally.

Because most patients in the ICU lack decisionmaking capacity, WhWd discussions are often shared between physicians, nurses, and family members or relatives acting as surrogates and representing the patient's values and preferences [21]. One important finding from this study is that decisions regarding WhWd are primarily founded on medical judgment. The low level of patients being directly or indirectly involved in the decision-making $(23 \%)$ may reflect that many were unable to express their preferences once hospitalized, and/ or that they did not anticipate such conditions of being before admission. While French Parliament unanimously passed the Leonetti law in 2005 after a long and highly publicized debate, the prevalence of advance directives or designated trusted person remains low. The availability and legal value of advance directives widely differ by country and show the balance between the culture of patient autonomy and that of paternalism in medical care [41]. In a survey of US citizens aged 60 years or older who have died of any cause between 2000 and 2010, the proportion of decedents with advance directives increased from $47 \%$ in 2000 to $72 \%$ in 2010 [42]. 


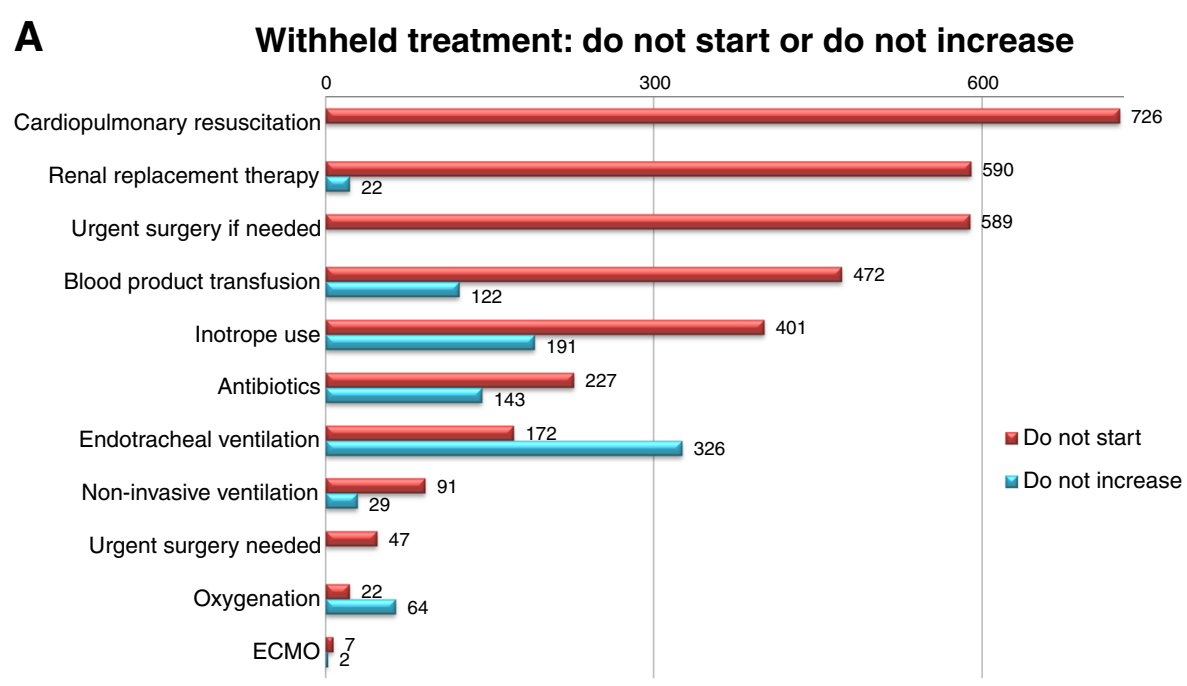

"Do not start" and "do not increase" orders are expressed as numbers of patients involved (of 777 WhWd)

B Withdrawn treatment

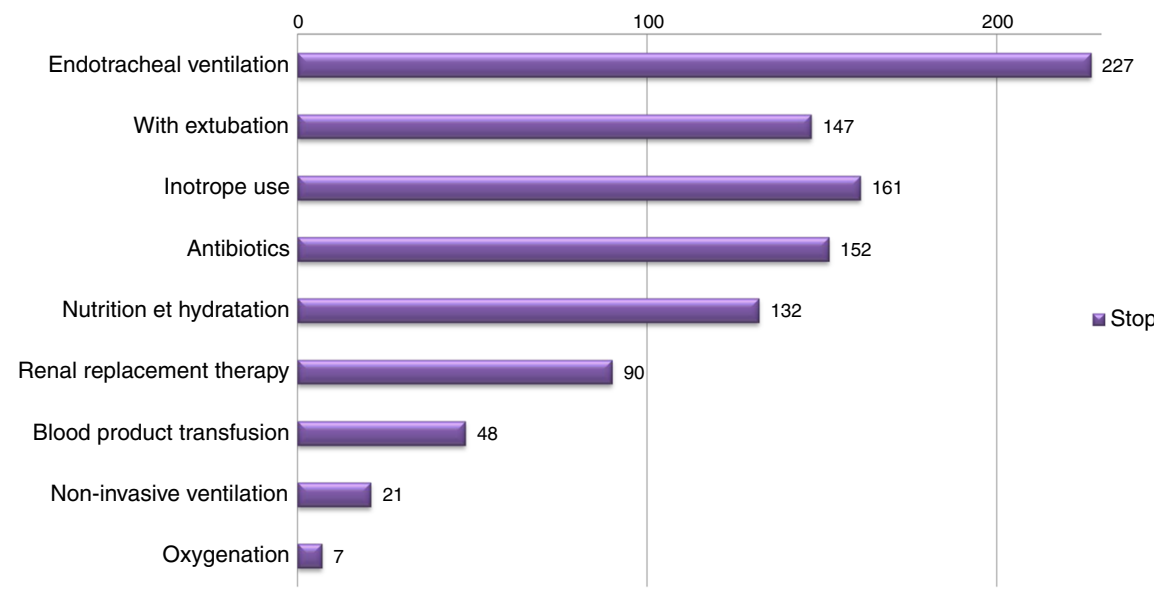

"Stop" orders are expressed as numbers of patients involved (of $433 \mathrm{Wd}$ )

Fig. 4 WhWd measures implemented separating "do not start," "do not increase," (a) and "stop" (b) orders. WhWd withhold or withdraw treatment, Wd withdraw treatment

According to the French law, the procedure should also involve an independent corroboration of the diagnosis and prognosis by an external physician who is missing in more than half the cases in our study. The rate of external corroboration is only slightly higher in case of treatment withdrawal (vs withholding). Whereas hospital specialists know best in their particular domains about the prognosis for diseases, it could be hypothesized that only skilled intensivists could assess the benefit-risk/ burden balance of life-sustaining therapies such as ventilatory support, inotrope use, renal replacement therapy, or extracorporeal oxygenator. Because many hospitals only have one ICU, referring to an independent and relevant arbitration may be challenging.
Treatment limitations in brain-injured patients differ from those applied to patients with end-stage irreversible diseases. In the former category (post-anoxic coma, stroke, head trauma), patients are rarely or never conscious at the time of the decision-making and cannot be involved in the discussion. Moreover, continuation of treatment may prolong life for months or years at the cost of being in a severely disabled state that such patients would not have accepted [41]. In our study, braininjured patients qualified for a WhWd procedure, who empirically had the poorest ability to participate directly in decision-making, were more likely to undergo withdrawal rather than withholding of treatment compared to patients with non-neurologic diseases. By comparison, 
Table 3 Baseline data and outcome of the 777 WhWd patients, separating withholding and withdrawal of treatment

\begin{tabular}{|c|c|c|c|}
\hline & $\begin{array}{l}\text { Withholding, } \\
N=344\end{array}$ & $\begin{array}{l}\text { Withdrawal, } \\
N=433\end{array}$ & $p$ \\
\hline Age (years) median (IQR) & $71(62-81)$ & $69(60-78)$ & 0.03 \\
\hline Male & $222(64.5)$ & $282(65.1)$ & 0.9 \\
\hline SAPS II median (IQR) & $55(44-70.5)$ & $62(50-75)$ & $<0.01$ \\
\hline Knaus $C$ and $D$ & $188(54.7)$ & $175(40.4)$ & $<0.01$ \\
\hline McCabe $=0$ & $129(37.5)$ & $186(43.0)$ & 0.12 \\
\hline Charlson score & $5(3-6)$ & $5(3-6)$ & 0.5 \\
\hline \multicolumn{4}{|l|}{ Chronic diseases: } \\
\hline Cardiac & 135 (39.2) & 147 (33.9) & 0.13 \\
\hline Pulmonary & $128(37.2)$ & $107(24.7)$ & $<0.01$ \\
\hline Neurological & $63(18.3)$ & $67(15.5)$ & 0.29 \\
\hline Renal & $50(14.5)$ & 59 (13.6) & 0.71 \\
\hline Vascular & $43(12.5)$ & $58(13.4)$ & 0.71 \\
\hline Hepatic & $30(8.7)$ & $47(10.9)$ & 0.32 \\
\hline Intestinal & $26(7.6)$ & $28(6.5)$ & 0.32 \\
\hline \multicolumn{4}{|l|}{ Neurological deficit: } \\
\hline Cognition & $51(14.5)$ & $43(9.9)$ & 0.02 \\
\hline Swallowing & $24(7.0)$ & $22(5.1)$ & 0.17 \\
\hline Hemiplegia & $9(2.6)$ & $13(3.0)$ & 0.46 \\
\hline Tetraplegia & $7(2.0)$ & $4(0.9)$ & 0.16 \\
\hline Malignancies & $90(26.2)$ & $131(30.3)$ & 0.20 \\
\hline Rare diseases & $17(4.9)$ & $27(6.2)$ & 0.27 \\
\hline \multicolumn{4}{|l|}{ Reasons for admission: } \\
\hline Respiratory failure & $139(40.4)$ & $120(27.7)$ & $<0.01$ \\
\hline Shock and MOF & $90(26.2)$ & $125(28.9)$ & 0.4 \\
\hline Brain injury & $67(19.5)$ & $156(36.0)$ & $<0.01$ \\
\hline Post-cardiac arrest & $48(14.0)$ & $102(23.6)$ & $<0.01$ \\
\hline Stroke & $13(3.8)$ & $36(8.3)$ & $<0.01$ \\
\hline Head trauma & $6(1.7)$ & $18(4.2)$ & 0.04 \\
\hline Other & $48(14.0)$ & $32(7.4)$ & $<0.01$ \\
\hline LOS (days) in the ICU median (IQR) & $9.5(4-24)$ & $7(3-17.5)$ & $<0.01$ \\
\hline Discharge alive from the ICU & $172(50.0)$ & $21(4.8)$ & $<0.01$ \\
\hline Delay WhWd to the last day in the ICU median (IQR) & $3(1-9)$ & $1(0-3)$ & $<0.01$ \\
\hline
\end{tabular}

Values are represented as number (\%), unless stated otherwise.

WhWd withhold or withdraw treatment, SAPS Simplified Acute Physiology Score, ICU intensive care unit, MOF multiple organ failure, LOS length of stay

patients with chronic respiratory diseases, pre-existing limited autonomy, and/or respiratory failure as reason for admission had treatment preferentially withheld than withdrawn in this study. One potential explanation is that prognostic indexes based on several factors in combination may predict outcome with better accuracy in neuro-critical care than in other areas in medicine [41, 43-46]. In case of brain injury, the predicted outcome measure is either death or poor functional fate. For patients with congestive cardiac failure, obstructive bronchitis, cirrhosis, kidney disease, or cancer, it is rarely possible to prognosticate with certainty that a chronically ill subject would not survive an acute episode [47]. These patients need to undergo a time-limited trial of intensive care prior to any prognostication or WhWd decision [13, 31, 48]. However, most prediction models were not developed with the specific aim of informing end-of-life decisions [12, 41].

Limiting treatments in critically ill patients does not mean forgoing chances of survival. In the ETHICUS study, the rate of patients discharged alive from the hospital after withholding and withdrawal was $11 \%$ (of 
Table 4 Organ failures, treatment already engaged, and rationales for WhWd at the time of the decision-making, separating withholding and withdrawal of treatment

\begin{tabular}{llll}
\hline & Withholding, & Withdrawal, & $p$ \\
& $N=344$ & $N=433$ & \\
\hline Total SOFA score median (IQR) & $5(3-9)$ & $9(5-13)$ & $<0.01$ \\
Total SOFA score $\geq 8$ & $122(35.5)$ & $260(60.0)$ & $<0.01$ \\
Total SOFA score $\geq 5$ & $198(57.6)$ & $367(84.8)$ & $<0.01$ \\
Total SOFA score $\geq 3$ & $282(82.0)$ & $418(96.5)$ & $<0.01$ \\
Respiratory failure & $119(34.6)$ & $182(42.0)$ & 0.03 \\
Neurologic failure & $104(30.2)$ & $281(64.9)$ & $<0.01$ \\
Circulatory failure & $103(29.9)$ & $192(44.3)$ & $<0.01$ \\
Hepatic failure & $10(2.9)$ & $37(8.5)$ & $<0.01$ \\
Hematologic failure & $14(4.1)$ & $54(12.5)$ & $<0.01$ \\
Renal failure & $56(16.3)$ & $118(27.3)$ & $<0.01$ \\
Treatments already engaged: & & & \\
$\quad$ Endotracheal ventilation & $213(61.9)$ & $375(86.6)$ & $<0.01$ \\
$\quad$ Non-invasive ventilation & $50(27.9)$ & $35(17.3)$ & $<0.01$ \\
Inotrope use & $107(31.1)$ & $206(47.6)$ & $<0.01$ \\
Renal replacement therapy & $24(7.2)$ & $100(23.6)$ & $<0.01$ \\
Antibiotics & $158(45.9)$ & $256(59.1)$ & $<0.01$ \\
Blood product transfusion & $46(14.9)$ & $77(18.6)$ & 0.11 \\
Surgery needed & $22(6.4)$ & $47(10.9)$ & 0.02 \\
Rationales to justify WhWd: & & & \\
No additional information needed & $246(78.1)$ & $356(90.8)$ & $<0.01$ \\
Limited subsequent autonomy & $252(80.3)$ & $329(81.4)$ & 0.34 \\
Absence of curative therapy & $199(61.4)$ & $360(86.5)$ & $<0.01$ \\
Non-responsive to treatment & $180(56.6)$ & $336(83.6)$ & $<0.01$ \\
End-stage incurable severe disease & $185(58.4)$ & $289(73.5)$ & $<0.01$ \\
Limited subsequent relational QOL & $177(57.7)$ & $265(68.3)$ & $<0.01$ \\
Limited autonomy before admission & $184(55.9)$ & $133(33.8)$ & $<0.01$ \\
Very advanced age & $101(31.9)$ & $109(27.9)$ & 0.14 \\
Excessive treatment felt by relatives & $59(18.9)$ & $113(28.2)$ & $<0.01$ \\
Patient's wish to limit treatment & $59(19.1)$ & $51(13.1)$ & 0.02 \\
\hline Valueness of patient's preferences & $86(25.0)$ & $95(21.9)$ & 0.31 \\
\hline $142(41.3)$ & $214(49.4)$ & 0.02 \\
\hline
\end{tabular}

Values are represented as number (\%), unless stated otherwise. SOFA sequential organ failure assessment, WhWd withhold or withdraw treatment, QOL quality of life. By convention, a SOFA organ sub-score of 3 or more was considered as organ failure

1594) and $1 \%$ (of 1398), respectively [3]. In the French LATAREA study, $43 \%$ of the Wh patients and $8 \%$ of the Wd patients left the ICU alive [2]. A recent study from Norway reported a survival rate on hospital discharge of 37 and $0 \%$ after withholding and withdrawal, respectively [49]. Our own survival rates on hospital discharge were $37 \%$ after withholding and $2 \%$ after withdrawal. Limitations did not solely involve patients who might die according to the physicians' judgment. Even though withholding and withdrawing therapy have been considered ethically equivalent $[21,22,31]$, our survey showed that in reality the more "active" limitations were associated with sudden and severe pathologies and the more "passive" with chronic diseases affecting respiration, autonomy, or cognition. Rather than ratifying a foretold death, the intention of the withholding decision was in some circumstances to let nature take its course toward death or life while avoiding non-beneficial and burdening therapies.

The current study has several strengths. Prospectively carried out in a large number of units throughout a single country, it identified conditions specifically associated with withholding or withdrawal of treatment. Limitations of treatment were described in details separating "do not start," "do not increase," and "stop" instructions. The study also showed that the rights to dispose of one's health conferred on citizens by law (advance directives, trusted person) were under-used, and as a result, that decisions remained under physicians' authority.

It also has limitations. First, it is uncertain whether the units involved in the study were representative of French practices. Second, information about sedation and analgesia given during the WhWd procedure (particularly Wd) was not collected. Third, neither the temporal steps of the WhWd procedure (first discussion, consensus reached within the staff, agreement obtained from families and/or relatives, implementation of the measures agreed) nor the prognostic indexes used to select patients for limitations were recorded.

\section{Conclusions}

In our study involving 43 French ICUs, more than half deaths occurred after a formal decision to withhold or withdraw therapies deemed non-beneficial. Brain-injured patients were more likely to undergo a withdrawal procedure, whereas patients with chronic respiratory disease and pre-existing disability affecting autonomy or cognition had treatment preferentially withheld than withdrawn. While the law authorizing such practices was passed in 2005, the prevalence of advance directives and designated trusted persons remains low. An external consultant was involved in less than half of all decisions. Because patients' wishes are rarely known at the time of the decision-making, limitations remained primarily based on medical judgment.

\footnotetext{
Abbreviations

BDD: brain determination of death; CDD: circulatory determination of death; $\mathrm{Cl}$ : confidence interval; FiO2: fraction of inspired oxygen; ICU: intensive care unit; IQR: interquartile; MD: missing data; OR: odds ratio; SAPS: Simplified Acute Physiology Score; SD: standard deviation; SOFA: Sequential Organ Failure Assessment; WhWd: withholding or withdrawing treatments.
}

\section{Competing interests}

The authors declare that they have no competing interests. 


\section{Authors' contributions}

$\mathrm{OL}, \mathrm{ML}$, and MFM designed the study. OL, ML, and ESG gathered the data. $\mathrm{OL}$ and $\mathrm{ML}$ performed the statistical analysis. OL, ML, and FG wrote the manuscript. OL had full access to all the data in the study and had final responsibility for the decision to submit for publication. All authors read and approved the manuscript.

\section{Acknowledgments}

This study was supported by the non-profit organizations AADAIRC (Association d'Aide à Domicile aux Insuffisants Respiratoires Chroniques) and OuestTransplant. The authors thank Marie-Line Cras, Nicolas Girard, and all the contributors (cited in the next paragraph) for their help in the implementation of the survey.

The EPILAT study group is composed of the following: Olivier Lesieur, Réanimation, CH Saint-Louis, 17019 La Rochelle, France; Maxime Leloup, Réanimation, CH Saint-Louis, 17019 La Rochelle, France; Frédéric Gonzalez, Réanimation Médico-Chirurgicale, CHU Avicenne, 93000 Bobigny, France; Marie-France Mamzer, EA 4569, Université Paris Descartes, 75006 Paris, France; Olivier Baudin, Réanimation, CH d'Angoulême, 16470 Saint-Michel, France; Martine Nyunga, Réanimation, CH Victor Provo, 59100 Roubaix, France; Julien Charpentier, Réanimation Médicale, CHU Cochin, 75014 Paris, France; Jean Louis Dubost, Réanimation, CH René Dubos, 95300 Pontoise, France; Laurent Martin Lefevre, Réanimation, CHD, 85000 La Roche-sur-Yon, France; Frédéric Guillaume, Réanimation, CH Saint-Louis, 17019 La Rochelle, France; Marina Thirion, Réanimation, CH Victor Dupouy, 95100 Argenteuil, France; Patrice Tirot, Réanimation, CH du Mans, 72037 Le Mans, France; Pascal Beuret, Réanimation, CH de Roanne, 42300 Roanne, France; Maud Jonas, Réanimation Médicale, CHU de Nantes, 44093 Nantes, France; Mickaël Moriconi, Réanimation, CH Cornouaille, 29107 Quimper, France; Jean Philippe Rigaud, Réanimation, CH de Dieppe, Dieppe 76200, France; Jean Pierre Quenot, Réanimation Médicale, CHU de Dijon, 21000 Dijon, France; Danielle Reuter, Réanimation Médicale, CHU Saint-Louis, 75010 Paris, France; René Robert, Réanimation Médicale, CHU de Poitiers, 86021 Poitiers, France; Nicolas Pichon, Réanimation Polyvalente, CHU Dupuytren, 86042 Limoges, France; Thierry Boulain, Réanimation Médicale, CHR d'Orléans, 45000 Orléans, France; Renaud Chouquer, Réanimation, CH d'Annecy, 74374 Pringy, France; Antoine Ausseur, Réanimation, CH de Cholet, 49300 Cholet, France; Fabrice Bruneel, Réanimation, CH de Versailles, 78150 Le Chesnay, France; Caroline Perreau, Réanimation, CHU de Fort de France, 97261 Fort de France, France; Benjamin Zuber, CHPOT, CH de Versailles, 78150 Le Chesnay, France; Alexandra Brionne, Réanimation, CH de Niort, 79000 Niort, France; Benoit Giraud, Réanimation neurochirurgicale, CHU de Poitiers, 86021 Poitiers, France; Xavier Tchenio, Réanimation, CH de Bourg-en-Bresse, 01012 Bourg-en-Bresse, France; Gérald Viquesnel, Réanimation Chirurgicale, CHU de Caen, 14033 Caen, France; Cécile Lory, Réanimation, CH de Guéret, 23011 Guéret, France; Malika Benrezkallah, Réanimation, CH de Valenciennes, 59300 Valenciennes, France; Diane Friedman, Réanimation, CHU Raymond Poincaré 92380 Garches, France; Jean Paul Gouello, Réanimation, CH de Saint Malo, 35400 Saint Malo, France; Thierry Vanderlinden, Réanimation, GHICL, 59462 Lomme, France; Michel Pinsard, Réanimation Chirurgicale, CHU de Poitiers, 86021 Poitiers, France; Benoit Misset, Réanimation, CH Saint Joseph, 75014 Paris, France; Emmanuel Antok, Réanimation, CHU Sud Réunion, 97448 Saint Pierre, France; Fabienne Plouvier, Réanimation, CH d'Agen, 47000 Agen, France; Didier Thevenin, Réanimation, CH Dr Schaffner, 62300 Lens, France; Marc-Olivier Fischer, Réanimation Chirurgie Cardiaque, CHU Caen, 14033 Caen, France; Olivier Gontier, Réanimation, CH de Chartres, 28630 Le Coudray, France; Marc Vinclair, Réanimation Neurochirurgicale, CHU Michallon, 38043 Grenoble, France; Christian Mirolo, Réanimation, CH Sud Essonne, 91152 Etampes, France; François Nicolas, Réanimation, CH de Châteauroux, 36000 Châteauroux, France; Willy-Serge Mfam, Réanimation Chirurgicale, CHR d'Orléans, 45000 Orléans, France; David Petitpas, Réanimation, CH de Chalons, 51000 Chalons en Champagne, France.

\section{Author details}

${ }^{1}$ Réanimation, CH Saint-Louis, 17019 La Rochelle, France. ²EA 4569, Université Paris Descartes, 75006 Paris, France. ${ }^{3}$ Réanimation Médico-Chirurgicale, CHU Avicenne, 93000 Bobigny, France.

Received: 14 January 2015 Accepted: 28 May 2015

Published online: 19 June 2015

\section{References}

1. Curtis JR, Sprung CL, Azoulay E. The importance of word choice in the care of critically ill patients and their families. Intensive Care Med. 2014;40:606-8.

2. Ferrand $E$, Robert $R$, Ingrand $P$, Lemaire F. Withholding and withdrawal of life support in intensive-care units in France: a prospective survey. French LATAREA group. Lancet. 2001;357:9-14.

3. Sprung $\mathrm{CL}$, Cohen SL, Sjokvist P, Baras M, Bulow H-H, Hovilehto S, et al. End-of-life practices in European intensive care units: the Ethicus study. JAMA. 2003;290:790-7.

4. Azoulay E, Metnitz B, Sprung CL, Timsit JF, Lemaire F, Bauer P, et al. End-of-life practices in 282 intensive care units: data from the SAPS 3 database. Intensive Care Med. 2009;35:623-30.

5. Frost DW, Cook DJ, Heyland DK, Fowler RA. Patient and healthcare professional factors influencing end-of-life decision-making during critical illness: a systematic review. Crit Care Med. 2011;39:1174-89.

6. Wilkinson DJC, Truog RD. The luck of the draw: physician-related variability in end-of-life decision-making in intensive care. Intensive Care Med. 2013;39:1128-32.

7. Sprung CL, Truog RD, Curtis JR, Joynt GM, Baras M, Michalsen A, et al. Seeking worldwide professional consensus on the principles of end-of-life care for the critically ill. The consensus for worldwide end-of-life practice for patients in intensive care units (WELPICUS) study. Am J Respir Crit Care Med. 2014;190:855-66.

8. Paruk F, Kissoon N, Hartog CS, Feldman C, Hodgson ER, Lipman J, et al. The Durban world congress ethics round table conference report: III. withdrawing mechanical ventilation-the approach should be individualized. J Crit Care. 2014;29:902-7.

9. Sprung CL, Paruk F, Kissoon N, Hartog CS, Lipman J, Du B, et al. The Durban world congress ethics round table conference report: I. differences between withholding and withdrawing life-sustaining treatments. J Crit Care. 2014;29:890-5.

10. Phua J, Joynt GM, Nishimura M, Deng Y, Myatra SN, Chan YH, et al. Withholding and withdrawal of life-sustaining treatments in intensive care units in Asia. JAMA Intern Med. 2015;175:363-71.

11. Zamperetti N, Piccinni P. Intensivists managing end-of-life care: dwarfs without giants' shoulders to stand upon. Intensive Care Med. 2010;36:1985-7.

12. Christakis NA. Death foretold: prophecy and prognosis in medical care. Chicago: University of Chicago Press; 2001.

13. Barnato AE, Tate JA, Rodriguez KL, Zickmund SL, Arnold RM. Norms of decision making in the ICU: a case study of two academic medical centers at the extremes of end-of-life treatment intensity. Intensive Care Med. 2012;38:1886-96

14. Bülow H-H, Sprung CL, Baras M, Carmel S, Svantesson M, Benbenishty J, et al. Are religion and religiosity important to end-of-life decisions and patient autonomy in the ICU? The Ethicatt study. Intensive Care Med. 2012;38:1126-33.

15. Quenot JP, Rigaud JP, Prin S, Barbar S, Pavon A, Hamet M, et al. Impact of an intensive communication strategy on end-of-life practices in the intensive care unit. Intensive Care Med. 2012;38:145-52.

16. Ouanes I, Stambouli N, Dachraoui F, Ouanes-Besbes L, Toumi S, Ben Salem $F$, et al. Pattern of end-of-life decisions in two Tunisian intensive care units: the role of culture and intensivists' training. Intensive Care Med. 2012;38:710-7.

17. Forte DN, Vincent JL, Velasco IT, Park M. Association between education in EOL care and variability in EOL practice: a survey of ICU physicians. Intensive Care Med. 2012;38:404-12.

18. Wilson ME, Rhudy LM, Ballinger BA, Tescher AN, Pickering BW, Gajic O. Factors that contribute to physician variability in decisions to limit life support in the ICU: a qualitative study. Intensive Care Med. 2013;39:1009-18.

19. Cook DJ, Guyatt G, Rocker G, Sjokvist P, Weaver B, Dodek P, et al. Cardiopulmonary resuscitation directives on admission to intensive-care unit: an international observational study. Lancet. 2001;358:1941-5.

20. Robert R, Salomon L, Haddad L, Graftieaux J-P, Eon B, Dreyfuss D. End of life in the intensive care unit: should French law be adapted? Ann Intensive Care. 2014:4:6.

21. Curtis JR, Vincent J-L. Ethics and end-of-life care for adults in the intensive care unit. The Lancet. 2010;376:1347-53.

22. Truog RD, Campbell ML, Curtis JR, Haas CE, Luce JM, Rubenfeld GD, et al. Recommendations for end-of-life care in the intensive care unit: a consensus statement by the American College [corrected] of Critical Care Medicine. Crit Care Med. 2008;36:953-63. 
23. Société de Réanimation de Langue Française. Limitation et arrêt des traitements en réanimation adulte. Actualisation des recommandations de la Société de réanimation de langue française. Réanimation. 2010;19:679-98.

24. Loi n² 2005-370 du 22 Avril 2005 relative aux droits des malades et à La fin de vie. J Off de La République Fran du 23 Avril 2005. Available from: http://legifrance.gouv.fr

25. Lesieur O, Leloup M, Gonzalez F, Mamzer M-F. Eligibility for organ donation following end-of-life decisions: a study performed in 43 French intensive care units. Intensive Care Med. 2014:40:1323-31.

26. Le Gall JR, Lemeshow S, Saulnier F. A new Simplified Acute Physiology Score (SAPS II) based on a European/North American multicenter study. JAMA. 1993;270:2957-63

27. Knaus WA, Zimmerman JE, Wagner DP, Draper EA, Lawrence DE. APACHEacute physiology and chronic health evaluation: a physiologically based classification system. Crit Care Med. 1981;9:591-7.

28. McCabe WR. Gram-negative bacteremia: I. Etiology and ecology. Arch Intern Med. 1962;110:847-55.

29. Charlson ME, Pompei P, Ales KL, MacKenzie CR. A new method of classifying prognostic comorbidity in longitudinal studies: development and validation. J Chronic Dis. 1987:40:373-83.

30. Vincent J-L, Moreno R, Takala J, Willatts S, De Mendonça A, Bruining H, et al. The SOFA (Sepsis-related Organ Failure Assessment) score to describe organ dysfunction/failure. Intensive Care Med. 1996;22:707-10.

31. Wilkinson D, Savulescu J. A costly separation between withdrawing and withholding treatment in intensive care. Bioethics. 2014;28:127-37.

32. Vincent JL. Forgoing life support in western European intensive care units: the results of an ethical questionnaire. Crit Care Med. 1999;27:1626-33.

33. Metaxa V, Lavrentieva A. End-of-life decisions in burn intensive care units - an international survey. Burns. 2015;41:53-7.

34. Bertolini G, Boffelli S, Malacarne P, Peta M, Marchesi M, Barbisan C, et al. End-of-life decision-making and quality of ICU performance: an observational study in 84 Italian units. Intensive Care Med. 2010;36:1495-504

35. Giannini A, Pessina A, Tacchi EM. End-of-life decisions in intensive care units: attitudes of physicians in an Italian urban setting. Intensive Care Med. 2003:29:1902-10.

36. Sprung CL, Carmel S, Sjokvist P, Baras M, Cohen SL, Maia P, et al. Attitudes of European physicians, nurses, patients, and families regarding end-of-life decisions: the ETHICATT study. Intensive Care Med. 2007;33:104-10.

37. Kübler A, Adamik B, Lipinska-Gediga M, Kedziora J, Strozecki L. End-of-life attitudes of intensive care physicians in Poland: results of a national survey. Intensive Care Med. 2011;37:1290-6.

38. Yaguchi A, Truog RD, Curtis JR, Luce JM, Levy MM, Mélot C, et al. International differences in end-of-life attitudes in the intensive care unit: results of a survey. Arch Intern Med. 2005;165:1970-5.

39. Esteban A, Gordo F, Solsona L, Alía I, Caballero J, Bouza C, et al. Withdrawing and withholding life support in the intensive care unit: a Spanish prospective multi-centre observational study. Intensive Care Med. 2001:27:1744-9.

40. Cook D, Rocker G, Marshall J, Sjokvist P, Dodek P, Griffith L, et al. Withdrawal of mechanical ventilation in anticipation of death in the intensive care unit. N Engl J Med. 2003;349:1123-32.

41. Geurts M, Macleod MR, van Thiel GJMW, van Gijn J, Kappelle LJ, van der Worp HB. End-of-life decisions in patients with severe acute brain injury. Lancet Neurol. 2014;13:515-24.

42. Silveira MJ, Wiitala W, Piette J. Advance directive completion by elderly Americans: a decade of change. J Am Geriatr Soc. 2014;62:706-10.

43. Verkade MA, Epker JL, Nieuwenhoff MD, Bakker J, Kompanje EJO. Withdrawal of life-sustaining treatment in a mixed intensive care unit: most common in patients with catastrophic brain injury. Neurocrit Care. 2012;16:130-5

44. Côte N, Turgeon AF, Lauzier F, Moore L, Scales DC, Bernard F, et al. Factors associated with the withdrawal of life-sustaining therapies in patients with severe traumatic brain injury: a multicenter cohort study. Neurocrit Care. 2013;18:154-60.

45. Kamps MJA, Horn J, Oddo M, Fugate JE, Storm C, Cronberg T, et al. Prognostication of neurologic outcome in cardiac arrest patients after mild therapeutic hypothermia: a meta-analysis of the current literature. Intensive Care Med. 2013;39:1671-82.
46. Parry-Jones AR, Abid KA, Napoli MD, Smith CJ, Vail A, Patel HC, et al. Accuracy and clinical usefulness of intracerebral hemorrhage grading scores: direct comparison in a UK population. Stroke. 2013;44:1840-5.

47. White DB, Ernecoff N, Billings J, Andrew EV, Arnold R. Is dying in an ICU a sign of poor quality end-of-life care? Am J Crit Care. 2013;22:263-6.

48. Quill TE, Holloway R. Time-limited trials near the end of life. JAMA. 2011;306:1483-4.

49. Hoel H, Skjaker SA, Haagensen R, Stavem K. Decisions to withhold or withdraw life-sustaining treatment in a Norwegian intensive care unit. Acta Anaesthesiol Scand. 2014;58:329-36.

\section{Submit your manuscript to a SpringerOpen ${ }^{\odot}$ journal and benefit from:}

- Convenient online submission

- Rigorous peer review

- Immediate publication on acceptance

- Open access: articles freely available online

- High visibility within the field

- Retaining the copyright to your article

Submit your next manuscript at $>$ springeropen.com 